Egyptian Journal of Aquatic Biology \& Fisheries

Zoology Department, Faculty of Science,

Ain Shams University, Cairo, Egypt.

ISSN $1110-6131$

Vol. 22(5): 257- 271 (2018)

www.ejabf.journals.ekb.eg

\title{
Effect of Methyl Farnesoate Administration on Ovarian Growth and Maturation in the Freshwater Crab Travancoriana schirnerae
}

Sudha Devi Arath Raghavan* and Aswani Ayanath

Department of Zoology, Mary Matha Arts \& Science College, Wayanad, India.

*Corresponding author: arsudhadevi@gmail.com

\begin{abstract}
ARTICLE INFO
Article History:

Received: Sept.25,2018

Accepted: Nov. 28, 2018

\section{Keywords:}

Freshwater crab

Maturation

Methyl farnesoate

Ovarian growth

T. schirnerae
\end{abstract}

Available online: Dec. 2018

\begin{abstract}
This study assessed the effect of exogenous administration of methyl farnesoate on growth and maturation of ovary in the freshwater crab Travancoriana schirnerae. Results provide strong evidence that methyl farnesoate administration induced ovarian growth in all phases of oogenesis as judged by the increased ovarian indices, oocyte diameter and oocyte proportion values of experimentals over controls. Our observations also revealed that methyl farnesoate treatment induced avitellogenic and previtellogenic ovaries to grow into vitellogenic and early vitellogenic to middle vitellogenic ovaries as evidenced by the presence of a large number of vitellogenic oocytes in avitellogenic and previtellogenic ovaries and enhanced yolk deposition in early vitellogenic ovaries. However, methyl farnesoate injection during late vitellogenic phase effected no significant change in morphology or histology of the ovary. From the results it is evident that methyl farnesoate administration caused a marked increase in gonial proliferation in both reproductive and non-reproductive phases. The elevated ovarian index, mean oocyte diameter and oocyte proportion values of experimentals over controls in the present investigation may be attributed to the increased growth and yolk deposition in oocytes triggered by methyl farnesoate. It is concluded that methyl farnesoate administration is effective in inducing ovarian growth and maturation thereby reducing the duration of the ovarian cycle which is highly advantageous for a species of aquaculture potential.
\end{abstract}

\section{INTRODUCTION}

In crustaceans, growth and reproduction are regulated by neuropeptides and steroid hormones. The stimulatory neuropeptides are the gonad stimulating hormone (GSH) secreted by the brain and thoracic ganglion while the inhibitory neuropeptides (gonad inhibiting hormone) are synthesized and released by the X-organ-sinus gland (XO-SG) complex of the eyestalk. Steroid hormones include ecdysone and methyl farnesoate (MF), synthesized and released by the Y-organ and the mandibular organ, respectively. The Y-organs are paired ectodermal endocrine glands, homologous to the prothoracic glands of insects and are the sources of the moulting hormone (MH) in crustaceans (Skinner, 1985; Chang, 1997). Mandibular organ (MO) is the only endocrine gland which synthesizes a terpenoid hormone, the MF, regulating moult and reproduction in adult crustaceans (Aiken, 1980; Laufer et al., 1994; Borst et al., 2001; 2002). 
Several studies indicated a stimulatory role for MF on reproduction in both male and female crustaceans. In vivo and in vitro experiments in Carcinus maenas, Uca pugilator and Oziotelphusa senex senex have shown a parallelism between MF production and ovarian development (Borst et al., 1987; Nagaraju et al., 2006). In Libinia emarginata, Laufer et al. (1987) found a positive correlation between the hemolymph titre of MF and the stage of development of the ovary. Further, in the same species, Sagi et al. (1993) observed elevated circulating titres of MF in reproductively active males compared to the inactive males. In vitro and in vivo stimulation of ovarian growth by MF has been reported for Penaeus vannamei (Tsukimura and Kamemoto, 1991). Rodriguez et al. (2002a) made observations on the effect of MF alone and its combination with other hormones on ovarian growth during vitellogenesis in the red swamp crayfish Procambarus clarkii. Nagaraju et al. (2003) reported MF induced gonad development in Macrobrachium malcolmsonii. Balasubramanian et al. (2010) studied the stimulation of ovarian growth by MF and eyestalk ablation (ESA) in the shrimp Sicyonia ingentis. Suneeta et al. (2010) elucidated the role of MF on reproduction in the tropical penaeid prawn Penaeus monodon.

Reddy et al. (2004) and Reddy and Reddy (2015) investigated the role of MF in regulating growth and vitellogenesis in the freshwater rice field crab $O$. senex senex. Reddy et al. (2016) studied the MF induced yolk protein synthesis in O. senex senex. Though ample literature is available regarding the stimulatory effects of MF on ovarian growth and maturation or spawning in marine decapods, literature is meager in freshwater brachyurans and a detailed study is required to establish this. In this context, the present investigation on the effect of exogenous administration of methyl farnesoate on ovarian growth and maturation in the edible freshwater crab Travancoriana schirnerae is undertaken.

\section{MATERIALS AND METHODS}

Adult intermoult female crabs (Carapace width $4.5-5 \mathrm{~cm}$ ) in various oogenic phases were collected monthly for a period of one year from the paddy fields of Ondayangadi and allowed to acclimatize to the conditions of the laboratory for 3-4 days. The animals were fed with cooked beef liver and pulses ad libitum and the water in the tubs was changed daily. The carapace width, wet weights and moult stages of animals were recorded. Moult stages were determined by examining the nature of the exoskeleton and setae of the epipodite of the 3rd maxilliped in males and pleopods in females.

Methyl farnesoate (trans, trans-MF), purchased from Echelon (Salt Lake City, USA), diluted with $10 \%$ ethanol was used for injection. The females in each oogenic phase (avitellogenic, previtellogenic and early, middle and late vitellogenic phases) were divided into three groups of 15 each. Group I served as initial control; Group II which received $10 \%$ ethanol formed the concurrent control. Group III which received $\mathrm{MF}$ at a dose of $25 \mathrm{ng} / \mathrm{g}$ bodyweight formed the experimentals. Injections were given on the first, seventh, fourteenth and twenty first day of experiment through the arthrodial membrane of the coxa of the $3^{\text {rd }}$ walking leg. Initial control animals were sacrificed on day first and the concurrent controls and experimentals on day 28. Their body weights and the wet weight of ovaries were recorded to calculate the ovarian index.

One half of the ovary was fixed in Bouins fluid and processed for histological studies and the other half for measuring oocyte diameter. Colour of ovary, oocyte 
diameter and ovarian index were the criteria used to determine the stage of development of the ovary. For histological observations, the stained sections were observed under a Leica DM 500 Research Microscope and light micrographs were taken with a Dewinter camera attachment using Biowizard software. Mean ovarian index, oocyte diameter, proportion of oocytes and histological characteristics were the criteria used to evaluate the impact of MF administration on ovarian maturation. The results were calculated as mean $\pm \mathrm{SD}$ and the differences in mean values of controls and experimentals were calculated using analysis of variance (ANOVA). A value of $\mathrm{P}<0.05$ was considered statistically significant.

\section{RESULTS}

The oogenic cycle of Travancoriana schirnerae was divided into five phases: avitellogenic, previtellogenic, early, middle and late vitellogenic. The current study analyzed the changes in morphological and histological characteristics of the ovary induced by MF administration during various phases of oogenesis in the edible freshwater crab T. schirnerae. Mean ovarian index, oocyte diameter, proportion of oocytes, gonial proliferation and rate of yolk deposition in oocytes were the criteria used to assess the effect.

\section{Effect of methyl farnesoate administration during avitellogenic phase}

The ovaries of control and concurrent control crabs of this phase were small, transparent and white with mean ovarian indices of $0.194 \pm 0.03$ and $0.198 \pm 0.02$ and mean oocyte diameter values of $67.25 \pm 8.50$ and $69.89 \pm 0.78 \mu \mathrm{m}$ respectively. Oogonia $(14.04 \pm 1.30 \mu \mathrm{m}$ diameter $)$ with large oval to spherical basophilic nuclei $(8.26 \pm 3.73 \mu \mathrm{m})$ were observed in the germinal zone of these ovaries. Close to the oogonia, chromatin nucleolus $(\mathrm{CN})$ stage 1 (diameter $35.77 \pm 10.12 \mu \mathrm{m})(8$ and $6 \%)$, $\mathrm{CN} 2(118.06 \pm 22.11 \mu \mathrm{m})(11$ and $13 \%)$ and $\mathrm{CN} 3(243.27 \pm 40.47 \mu \mathrm{m})(9$ and $7 \%)$ oocytes were orderly arranged together with a small percentage of perinuclear (PN) $(359.28 \pm 22.52 \mu \mathrm{m})(23$ and $24 \%)$ oocytes in the peripheral zone. The CN oocytes were oval or elongate with granular, mildly basophilic ooplasm and round to oval, centrally placed multinucleolated (2-5) $(7.35 \pm 3.00 \mu \mathrm{m}$ diameter) nuclei $(31.46 \pm 15.23$ $\mu \mathrm{m})$. Perinuclear oocytes contained $2-4$ highly basophilic nucleoli $(8.50 \pm 3.67 \mu \mathrm{m})$ inside their oval or round basophilic nuclei $(59.28 \pm 15.29 \mu \mathrm{m}$ diameter). Furthermore, large number of shrunken follicles, atretic oocytes and pycnotic follicle nuclei were seen scattered in the ovary. The $\mathrm{CN}$ and PN oocytes were seen surrounded by a large number of oval, basophilic, multinucleolated follicle nuclei.

Ovaries of MF treated crabs resembled morphologically with that of control groups but showed a substantial increase in mean ovarian index $(0.223 \pm 0.02)$ and oocyte diameter values $(80.77 \pm 11.11 \mu \mathrm{m})$ and changes in histological features from the control groups (Table 1). Furthermore, treated crabs displayed an increase in gonial cell proliferation $(53 \% ; \mathrm{F}$ value $=23.51 ; \mathrm{P}<0.05)$ compared to the untreated control groups (49 and 50\%) (Fig. 1A). Histological observations of treated ovaries showed the presence of large number of follicle cells surrounding the $\mathrm{CN}$ and PN oocytes. In some treated crabs, the follicle cells were seen in clusters besides forming epithelium around the $\mathrm{CN}$ and $\mathrm{PN}$ oocytes and the proportion of shrunken follicles, atretic oocytes and pycnotic follicle nuclei was seen considerably reduced than the control groups. The most notable feature in ovaries of treated crabs was the presence of early vitellogenic oocytes (12\%). 
Table 1: Impact of methyl farnesoate administration on ovarian index and mean oocyte diameter during various phases of oogenesis in the freshwater crab T. schirnerae

\begin{tabular}{|l|l|l|l|l|l|}
\hline Phases of oogenesis & Group & \multicolumn{3}{l|}{ Ovarian index } & \multicolumn{2}{l|}{ Mean oocyte diameter $(\mu \mathrm{m})$} \\
\cline { 2 - 5 } & & Mean \pm SE & F value & Mean \pm SE & F value \\
\hline Avitellogenic & Control & $0.194 \pm 0.03$ & & $67.25 \pm 8.50$ & \\
(April-May) & Concurrent control & $0.198 \pm 0.02$ & 0.009 & $69.89 \pm 0.78$ & 0.305 \\
& MF treated & $0.223 \pm 0.02$ & 0.565 & $80.77 \pm 11.11$ & 0.917 \\
\hline Previtellogenic & Control & $0.280 \pm 0.01$ & & $385.29 \pm 12.76$ & \\
(Jun-Sep) & Concurrent control & $0.282 \pm 0.004$ & 0.472 & $386.79 \pm 3.78$ & 0.295 \\
& MF treated & $0.291 \pm 0.01$ & 1.100 & $397.53 \pm 13.79$ & 0.417 \\
\hline Early vitellogenic & Control & $0.481 \pm 0.02$ & & $489.43 \pm 4.03$ & \\
(Oct- Nov) & Concurrent control & $0.507 \pm 0.02$ & 0.092 & $490.55 \pm 5.33$ & 0.396 \\
& MF treated & $0.541 \pm 0.02$ & $4.275^{*}$ & $504.881 \pm 2.75$ & $10.745^{*}$ \\
\hline Middle vitellogenic & Control & $1.021 \pm 0.08$ & & $778.99 \pm 37.66$ & \\
(Dec-Feb) & Concurrent control & $1.055 \pm 0.10$ & 0.007 & $785.74 \pm 36.30$ & 0.016 \\
& MF treated & $1.427 \pm 0.11$ & $8.359 *$ & $916.86 \pm 45.49$ & $5.522^{*}$ \\
\hline Late vitellogenic & Control & $4.036 \pm 0.16$ & & $1398.68 \pm 36.42$ & \\
(Mar) & Concurrent control & $4.080 \pm 0.10$ & 0.082 & $1400.69 \pm 39.87$ & 0.001 \\
& MF treated & $4.502 \pm 0.61$ & 0.874 & $1444.29 \pm 28.07$ & 0.984 \\
\hline
\end{tabular}

$* P<0.05$
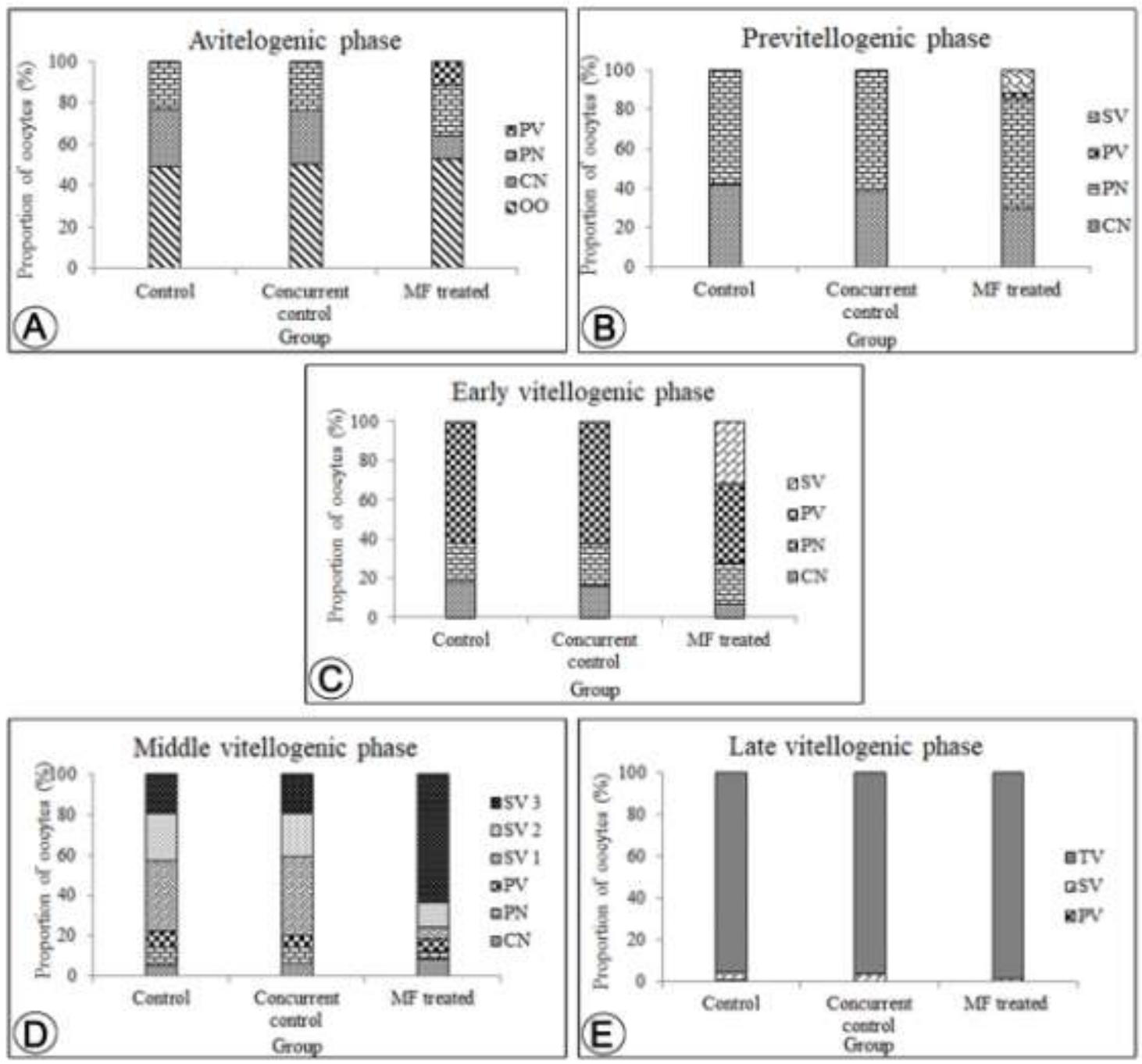

Fig. 1. Impact of MF administration on proportion of oocytes during various phases of oogenesis in Travancoriana schirnerae. (A) Avitellogenic phase (B) Previtellogenic phase (C) Early vitellogenic phase (D) Middle vitellogenic phase (E) Late vitellogenic phase. 
The peripheral ooplasm of these oocytes demonstrated the presence of highly basophilic yolk granules and vacuolated globules indicating signs of vitellogenesis (Figs. 2A-E).
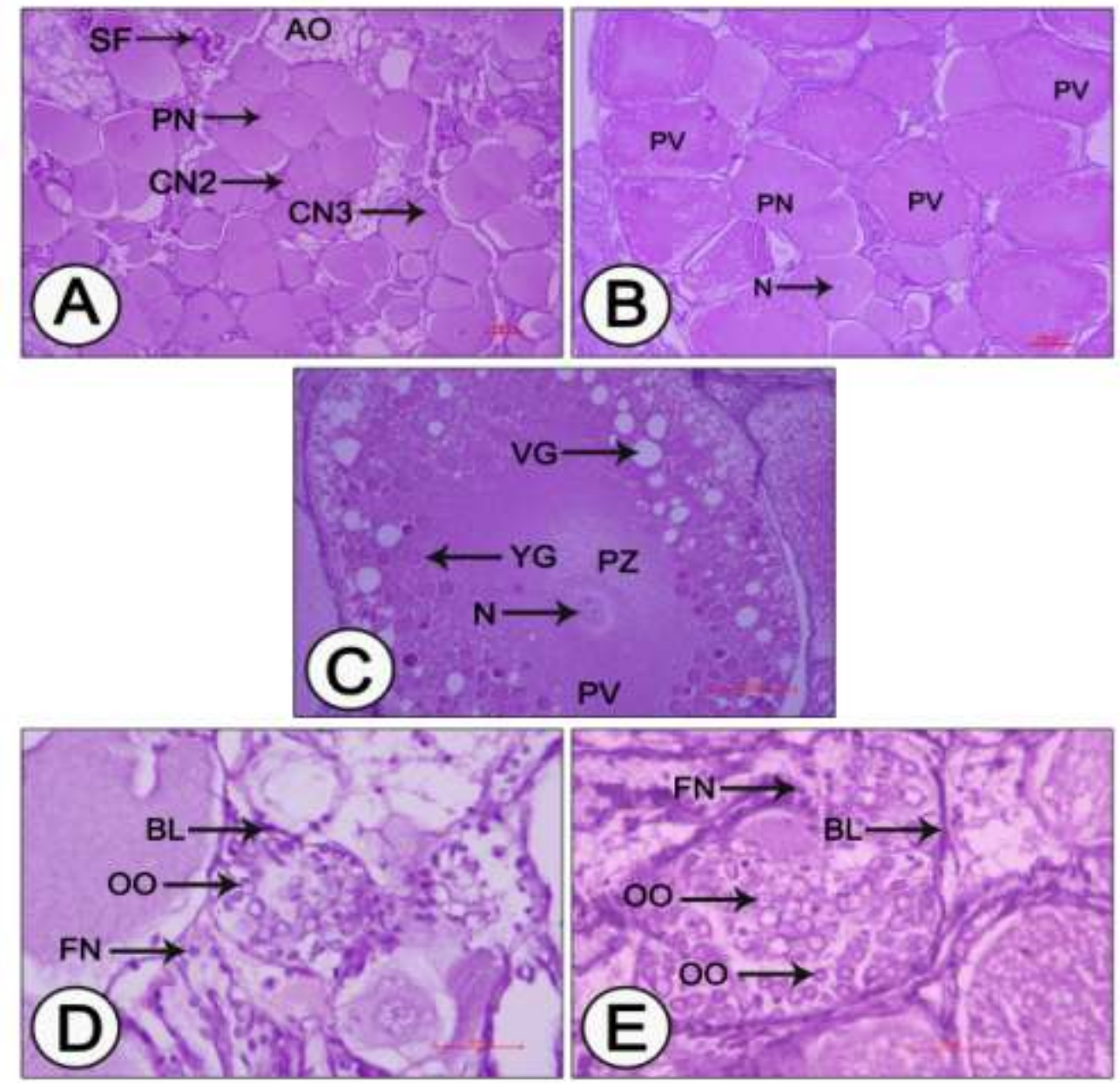

Fig. 2: Histology of control and experimental ovaries during avitellogenic phase. (A) Avitellogenic ovary of control crab showing CN, PN oocytes, shrunken follicles and atretic oocytes (B) Ovary of MF administered crab showing primary vitellogenic oocytes (D-E) Oogonial proliferation in ovaries of control and treated crabs (C) Primary vitellogenic oocyte with vacuolated globules and basophilic yolk granules in the cortical region.

AO: Atretic oocyte; BL: Basal lamina; CN2: Chromatin nucleolus stage 2 oocyte; CN3: Chromatin nucleolus stage 3 oocyte; FN: Follicle nucleus; N: Nucleus; OO: Oogonia; PN: Perinuclear stage oocyte; PV: Primary vitellogenic oocyte; PZ: Perinuclear zone; SF: Shrunken follicle; VG: Vacuolated globule; YG: Yolk globule.

\section{Effect of methyl farnesoate administration on ovarian growth during previtellogenic phase}

Methyl farnesoate injection did not cause any appreciable change in morphology but caused considerable changes in histological features. The ovaries were small, transparent and cream-coloured with the mean ovarian index and oocyte diameter values $(0.280 \pm 0.01$ and $385.29 \pm 12.76 \mu \mathrm{m}$ respectively) of controls on par with the corresponding values of concurrent controls $(0.282 \pm 0.004$ and $386.79 \pm 3.78$ $\mu \mathrm{m}$ respectively). However, there was an insignificant rise in the ovarian index and mean oocyte diameter values $(0.291 \pm 0.01$ and $397.53 \pm 13.79 \mu$ m respectively) from that of controls (Table 1). The ovary in control groups showed a predominance of $\mathrm{CN}$ (41 and 38\% respectively) and PN (59 and 62\% respectively) stage oocytes with a small proportion of oogonia (Fig. 1B) whereas injected crabs displayed significantly 
large number of oogonia $(\mathrm{F}$ value $=10.31 ; \mathrm{P}<0.05)$ and $\mathrm{PN}$ oocytes $(56 \%)$ and less number of $\mathrm{CN}$ oocytes (29\%) (Fig. 3A-F).
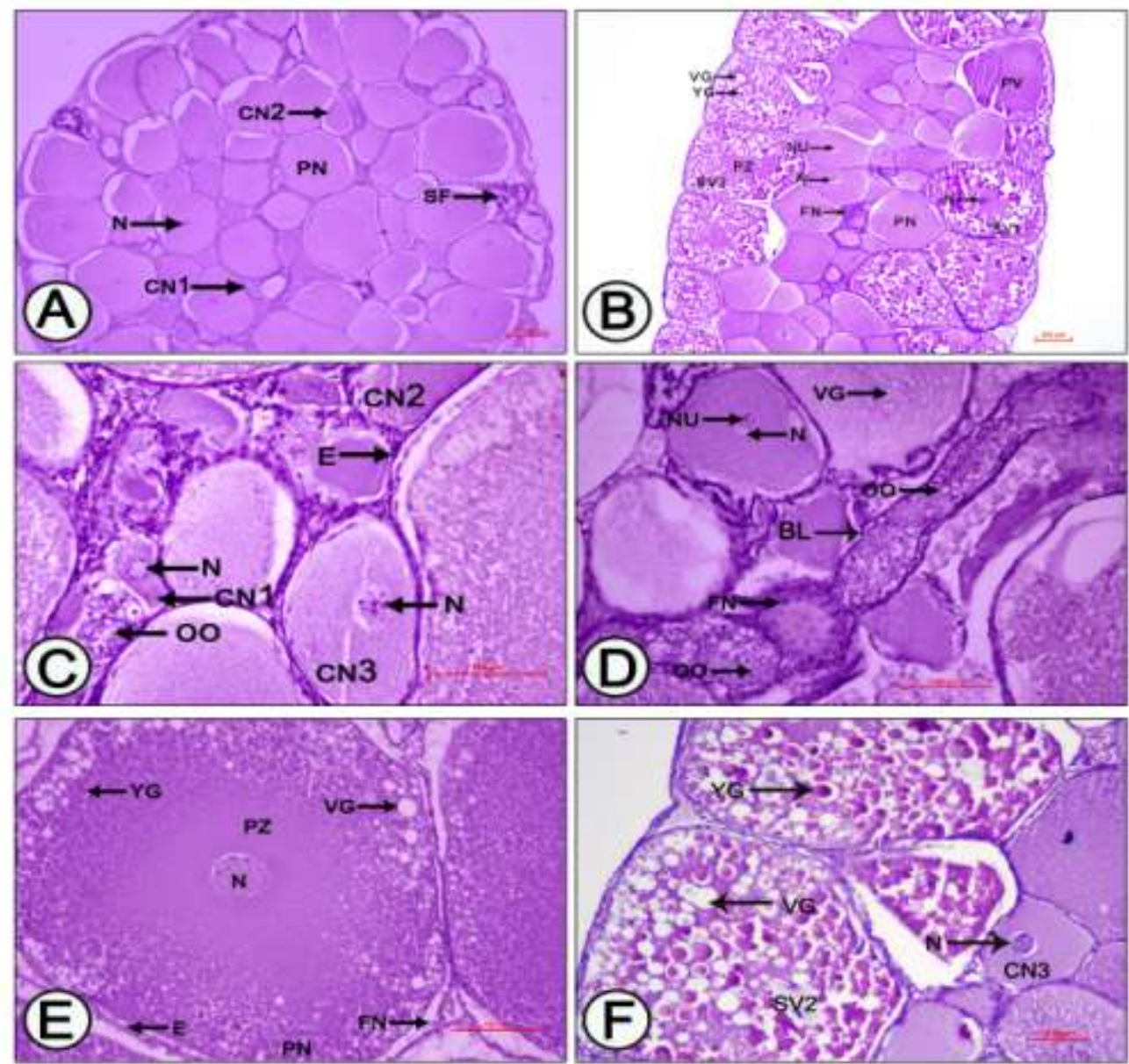

Fig. 3. Light micrograph of ovary of control and MF administered crab during previtellogenic phase. (A) Previtellogenic ovary of control crabs populated by chromatin nucleolus and perinuclear stage oocytes (B) Secondary vitellogenic oocytes in ovary of treated crab (C-D) Germinative islets in ovaries of control and treated crabs (E) Peripheral ooplasm of perinuclear oocyte displaying signs of yolk deposition in ovary of injected crab (F) Secondary vitellogenic oocytes in treated ovary.

BL: Basal lamina; CN1: Chromatin nucleolus stage 1 oocyte; CN2: Chromatin nucleolus stage 2 oocyte; CN3: Chromatin nucleolus stage 3 oocyte; E: Epithelium; FN: Follicle nucleus; N: Nucleus; NU: Nucleolus; OO: Oogonia; PN: Perinuclear stage oocyte; PV: Primary vitellogenic oocyte; PZ: Perinuclear zone; SF: Shrunken follicle; SV1: Secondary vitellogenic stage 1 oocyte; SV2: Secondary vitellogenic stage 2 oocyte; VG: Vacuolated globule; YG: Yolk globule

The most striking feature of ovaries in treated crabs were the presence of a large number of vitellogenic oocytes (primary and secondary vitellogenic oocytes 3 and $12 \%$ respectively) arranged towards the periphery. The CN and PN oocytes at this stage were encircled by a single layer of epithelium while the vitellogenic oocytes were seen surrounded by a double layered epithelium (Figs. 3A-F). In addition, the experimental group displayed a remarkable increase in gonial proliferation.

\section{Effect of administration of methyl farnesoate during early vitellogenic phase.}

The ovary acquired a light yellowish hue by the time it reached early vitellogenic phase and recorded ovarian indices of $0.481 \pm 0.02$ and $0.507 \pm 0.02$ and oocyte diameter values of $489.43 \pm 4.03$ and $490.55 \pm 5.33 \mu \mathrm{m}$ for control and 
concurrent controls respectively. On the other hand, the injected crabs had higher values for ovarian index $(0.541 \pm 0.02)$ and mean oocyte diameter $(504.88 \pm 2.75 \mu \mathrm{m})$ which differed statistically from the controls $(\mathrm{P}<0.05)$ (Table 1$)$. The ovaries of control groups were dominated by PV oocytes (62 and $63 \%$ respectively) followed by PN (20 and $21 \%$ respectively) and CN stage oocytes (18 and 16\% respectively) (Fig. 1C) whereas the experimental ovaries had $32 \%$ oocytes in secondary, $40 \%$ in primary vitellogenic, 21 and 7\% in PN and CN stages respectively. Histological appearance of the ovary of treated crabs suggested that the degree of yolk deposition was high in vitellogenic oocytes of treated crabs than those in the untreated controls. In control crabs, the peripheral ooplasm of primary vitellogenic (PV) oocytes was occupied by very few small vacuolated globules $(15-25 \mu \mathrm{m})$ and mildly basophilic yolk granules $(7.5-15 \mu \mathrm{m})$ whereas the primary oocytes of treated crabs were characterized by the presence of numerous large vacuolated globules $(20-30 \mu \mathrm{m})$ and yolk granules $(15-25$ $\mu \mathrm{m})$ and secondary vitellogenic (SV) oocytes with large vacuolated globules (35-47 $\mu \mathrm{m}$ diameter) and yolk platelets (29-53 $\mu \mathrm{m}$ width) (Figs. 4A-E). Besides, the experimental crabs exhibited a significant enhancement in gonial proliferation over the controls $(\mathrm{F}$ value $=8.03, \mathrm{P}<0.05)$.

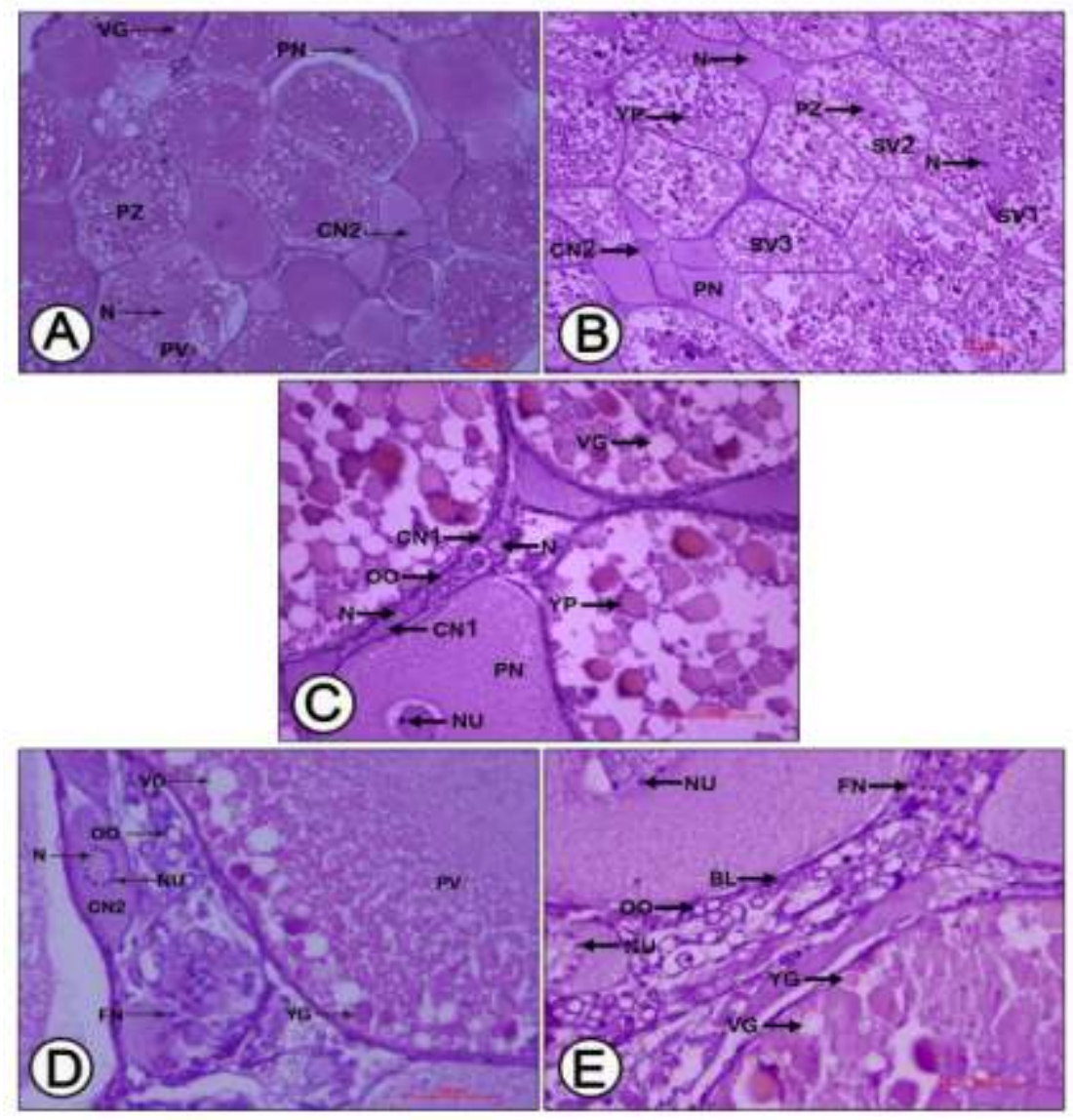

Fig. 4: Ovary of control and MF administered crabs during early vitellogenic phase. (A) Ovary of control crab (B) Ovary of MF administered crab with secondary vitellogenic oocytes (C) Vacuolated globules and yolk platelets in secondary oocytes of injected crab (D-E) Ovary of control and treated crab with oogonial nests.

BL: Basal lamina; CN1: Chromatin nucleolus stage 1 oocyte; CN2: Chromatin nucleolus stage 2 oocyte; FN: Follicle nucleus; N: Nucleus; NU: Nucleolus; OO: Oogonia; PN: Perinuclear stage oocyte; PV: Primary vitellogenic oocyte; PZ: Perinuclear zone; SV1: Secondary vitellogenic stage 1 oocyte; SV2: Secondary vitellogenic stage 2 oocyte; SV3: Secondary vitellogenic stage 3 oocyte; VG: Vacuolated globule; YG: Yolk globule; YP: Yolk platelet. 


\section{Effect of methyl farnesoate administration during middle vitellogenic phase}

The ovaries of both controls and concurrent controls recorded mean ovarian indices of $1.021 \pm 0.08$ and $1.055 \pm 0.10$ and mean oocyte diameter values of $778.99 \pm 37.66$ and $785.74 \pm 36.30 \mu \mathrm{m}$ respectively (Table 1 ). In contrast, the experimentals displayed significantly higher values for ovarian index and mean oocyte diameter $(1.427 \pm 0.11$ and $916.86 \pm 45.49 \mu \mathrm{m}$ respectively; $\mathrm{P}<0.05)$ indicating that MF administration stimulated ovarian growth. The SV oocytes were observed with a diameter of $725.50 \pm 34.73 \mu \mathrm{m}$ and their nuclei measured $37.36 \pm 7.28 \mu \mathrm{m}$ with single large nucleoli. These oocytes have large yolk platelets $(35-57 \mu \mathrm{m})$ and vacuolated globules $(34-57 \mu \mathrm{m})$ which extend deep into the ooplasm towards the nucleus (5A-E). Though SV oocytes dominated the ovaries of both controls (78 and $80 \%$ respectively) and treated group (82\%), the proportion of SV stage 3 (SV3) oocytes was remarkably high in treated crabs $(64 \%)$ than the control groups $(20 \%$ each) (Fig. 1D). Moreover, the injected crabs displayed a higher proportion of gonia than the control groups $(\mathrm{F}$ value $=7.60 ; \mathrm{P}<0.05)$.

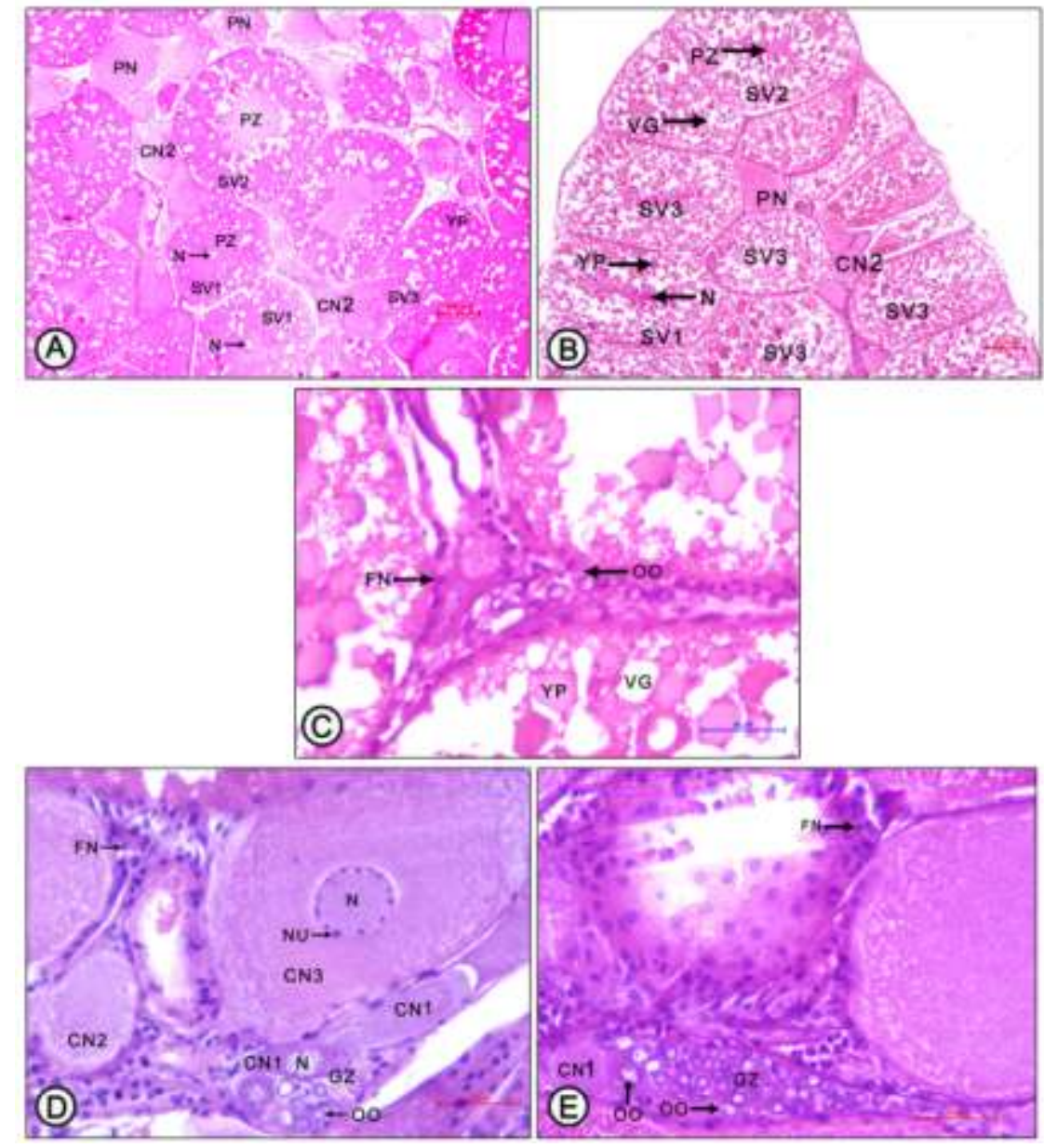

Fig. 5. Light micrograph of ovary of control and MF administered crab during middle vitellogenic phase. (A) Ovary of control crabs dominated by SV1 oocytes (B) Treated ovaries dominated by SV3 oocytes (C) Ovary of control crab with a few oogonia in the germinal zone (D) Oogonia and $\mathrm{CN}$ oocytes in the ovary of MF administered crab (E) Gonial proliferation in the ovary of treated crab.

CN1: Chromatin nucleolus stage 1 oocyte; CN2: Chromatin nucleolus stage 2 oocyte; CN3: Chromatin nucleolus stage 3 oocyte; FN: Follicle nucleus; GZ: Germinal zone; N: Nucleus; NU: Nucleolus; OO: Oogonia; PN: Perinuclear stage oocyte; PZ: Perinuclear zone; SV1: Secondary vitellogenic stage 1 oocyte; SV2: Secondary vitellogenic stage 2 oocyte SV3: Secondary vitellogenic stage 3 oocyte; VG: Vacuolated globule; YP: Yolk platelet. 


\section{Effect of methyl farnesoate administration during late vitellogenic phase}

The ovaries of crabs treated with $\mathrm{MF}$ during this phase resembled morphologically and histologically to those of control groups. The ovary appeared large with an orange tinge and was mainly composed of compactly packed tertiary vitellogenic oocytes (95 and 96\% respectively) followed by a few SV (4\% each) and PV oocytes (1 and $0 \%$ respectively) (Fig. 1E). The ovarian index value reached its peak during this phase and the tertiary vitellogenic oocytes accomplished a maximum size of $1500 \mu \mathrm{m}$ (diameter) with their nuclei becoming totally indistinguishable. The large eosinophilic yolk platelets have fused to form a homogenous matrix and the follicle epithelium was no longer apparent around the oocytes, reduced to a thin basophilic membrane (Figs. 6A-D). Though the experimental group (MF injected) had elevated values for ovarian index $(4.502 \pm 0.61)$ and mean oocyte diameter $(1444.29 \pm 28.07)$ than their respective controls $(4.036 \pm 0.16$ and $1398.68 \pm 36.42 \mu \mathrm{m}$ respectively) and concurrent controls (4.080 \pm 0.10 and $1400.69 \pm 39.87$ respectively), these differences were insignificant statistically $(\mathrm{P}>0.05)$ (Table 1).

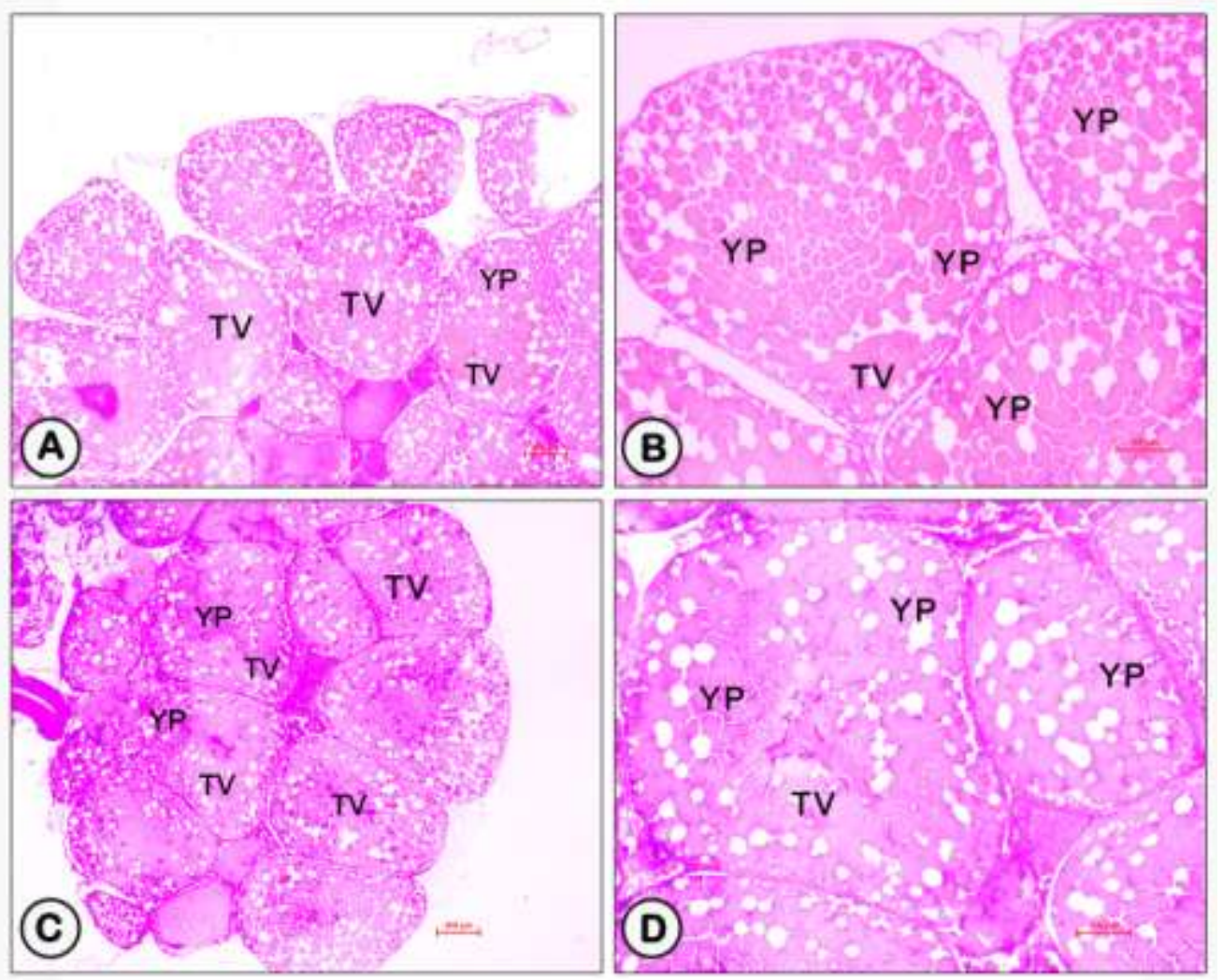

Fig. 6. Control and treated ovary during late vitellogenic phase showing compactly packed tertiary vitellogenic oocytes (A) Ovary of control crab (B) A portion of the control ovary at higher magnification (C) Ovary of treated crab (D) A portion of the treated ovary at higher magnification.

TV: Tertiary vitellogenic oocyte; YP: Yolk platelet.

\section{DISCUSSION}

The present study explicated the effect of exogenous administration of MF on ovarian growth and maturation in the freshwater crab $T$. schirnerae. Results of this study provide strong evidence that administration of MF induced ovarian growth in all phases of oogenesis as judged by the increased ovarian indices, oocyte diameter and oocyte proportion values, gonial proliferation, presence of large number of 
vitellogenic oocytes in avitellogenic and previtellogenic ovaries and increased yolk deposition in vitellogenic ovaries of experimentals over controls.

The gonadotropic effect of MF was reported in many crustaceans (Borst et al., 1987; Laufer et al., 1998; Nagaraju et al., 2006; Nagaraju and Borst, 2008; Nagaraju, 2011). Administration of MF enthused vitellogenesis and gonad maturation in some crayfishes and crabs (Laufer, 1992; Kalavathy et al., 1999; Rotllant et al., 2000; Nagaraju, 2007). For instance, Landau et al. (1989) and Reddy and Ramamurthi (1998) have shown a positive correlation between administration of MF and ovarian maturation in $P$. clarkii and $O$. senex senex. On the contrary, MF does not stimulate ovarian development in Homarus americanus, $M$. rosenbergii and Cherax quadricarinatus (Tsukimura et al., 1993; Wilder et al., 1994; Abdu et al., 2001). Tsukimura et al. (2006) reported inhibition of ovarian development by MF in the tadpole shrimp Triops longicaudatus.

Several authors suggested the role of vertebrate type steroid sex hormones in inducing ovarian growth and maturation in crustaceans (Nagabhushanam et al., 1987; Sarojini et al., 1990; Zapata et al., 2003). Both in vivo and in vitro administration of $17 \beta$-estradiol and $17 \alpha-\mathrm{OH}$ progesterone induced vitellogenesis and ovarian maturation in the tiger prawn P. monodon (Merlin et al., 2015). Progesterone and pregnenolone augmented ovarian growth and vitellogenin synthesis has been reported in O. senex senex (Reddy et al., 2006), Barytelphusa cunicularis (Kale et al., 2008) and Scylla olivacea (Muhd-Farouk et al., 2016). On the other hand, a negative correlation exists between ovarian maturation and vertebrate steroids in P. clarkii (Rodriguez et al., 2002b) and Marsupenaeus japonicus (Okumura and Sakiyama, 2004).

The observations of the present investigation revealed an enhancement in ovarian index, mean oocyte diameter values and oocyte proportion of experimentals over controls. In support of this research, elevated values for ovarian index, oocyte diameter, testicular index and follicle diameter were obtained by Nagaraju et al. (2002; 2003) in P. indicus and M. malcolmsonii treated with MF. Reddy and Reddy (2015) and Reddy et al. (2016) have shown increased ovarian indices, oocyte diameter and ovarian vitellogenin levels in MF injected $O$. senex senex. Hemalatha et al. (2016) have recorded significantly high oocyte diameter, ovarian index, and ovarian vitellin levels following eyestalk ablation (ESA) and MF administration. A similar acceleration in oocyte diameter, ovarian index and ovarian vitellogenin levels was found in $O$. senex senex following administration of estradiol and progesterone (Reddy et al., 2006; Swetha et al., 2016). Fairs et al. (1990) found that $17 \alpha-\mathrm{OH}$ progesterone, MF and juvenile hormone III (JH III) significantly increased $P$. vannamei oocyte diameter in vitro. In crustaceans, ovarian index, colour of ovary, oocyte diameter, vitellogenin titre of hemolymph and lipovitellin deposition in oocytes were considered as measures to determine ovarian maturation (CharniauxCotton and Payen, 1988; Tsukimura, 2001). The elevated ovarian index, mean oocyte diameter and oocyte proportion values of experimentals over controls in the present investigation may be attributed to the increased growth and yolk deposition in oocytes triggered by MF.

Our observations also revealed that MF treatment induced avitellogenic and previtellogenic ovaries to grow into vitellogenic and early vitellogenic to middle vitellogenic ovaries as evidenced by the presence of a large number of vitellogenic oocytes in avitellogenic and previtellogenic ovaries and enhanced yolk deposition in early vitellogenic ovaries. These results are in agreement with the findings of Sasikala and Subramoniam (1991) in the crab Paratelphusa hydrodromous where 
they found enhanced yolk deposition after injection of JH III. The ovaries of prereproductive females developed into late vitellogenic ovaries by 30 days MF treatment in $P$. clarkii (Laufer et al., 1998). Nagaraju et al. (2003) observed that in $O$. senex senex, the ovaries of experimentals reached late vitellogenic stage following treatment with MF while the untreated controls remained in early vitellogenic stage. Reddy et al. (2016) have shown enhanced vitellogenin levels following MF administration in $O$. senex senex. Similar observations were made with estradiol and progesterone treatment in several crustaceans (Yano and Hoshino, 2006; Coccia et al., 2010; Merlin et al., 2015; Sujathamma and Dayakar, 2015). Methyl farnesoate in combination with 17-OH progesterone during postreproductive period stimulated vitellogenesis in the estuarine crab Neohelice granulata (Medesani et al., 2015). It is possible that MF may facilitate the deposition of high amounts of yolk in oocytes thereby increasing the size of oocytes and growth and maturation of ovary (Hemalatha et al., 2016).

In T. schirnerae, MF injection during late vitellogenic phase effected no significant change in morphology or histology of the ovary. In the same way, no positive or stimulatory effect was observed when $T$. longicaudatus ovary was incubated with MF in late vitellogenic stage (Riley and Tsukimura, 1998). Furthermore, Kraisuwansopit et al. (2008) established that MF has no role in postvitellogenesis or spawning in adult female crabs.

From the results it is evident that MF administration resulted in a marked increase in gonial proliferation in both reproductive and nonreproductive phases. Similar results were obtained in Parapenacopsis stylifera, where exogenous progesterone stimulated proliferation of oocytes (Joshi, 1980). Nagabhushanam et al. (1987) observed that the ovaries of the freshwater prawn Caridina rajadhari injected with leutinizing ( $\mathrm{LH})$ and follicle stimulating hormone (FSH) enclosed more number of oogonia, follicle cells and germinative oocytes than the uninjected controls. Brandau (1970) was of the opinion that progesterone induces development of germ cells and gonial proliferation in crustaceans. In Metapenaeus monoceros, LH and human chorionic goadotropin (HCG) have stimulatory roles on early stages of oogenesis and less influence on vitellogenic oocytes (Kulkarni et al., 1979).

\section{CONCLUSION}

To conclude, methyl farnesoate administration is effective in inducing ovarian growth and maturation in $T$. schirnerae as indicated by the elevated ovarian index, oocyte diameter and oocyte proportion values, initiation of vitellogenesis in avitellogenic and previtellogenic ovaries and enhanced yolk deposition in early vitellogenic oocytes of treated crabs over controls. Eyestalk ablation, the most commonly practiced method to induce ovarian maturation and spawning in hatcheries often leads to inferior quality seeds or poor hatchability. Knowledge generated from this research can be utilized as an alternate way to induce ovarian growth and maturation in hatcheries without compromising seed quality.

\section{ACKNOWLEDGMENT}

The financial support provided by the Kerala State Council for Science Technology \& Environment (Order No. P 115/2016/KSCSTE dated. 03-05-2016) in carrying out this research is gratefully acknowledged. 


\section{AUTHORS CONTRIBUTIONS}

ARS designed the experiment and wrote the paper. AA carried out the experiment and analyzed the data.

\section{CONFLICT OF INTEREST}

The authors declare that there is no conflict of interests regarding the publication of this article.

\section{REFERENCES}

Abdu, U.; Barki, A.; Karplus, I.; Barel, S.; Takac, P.; Yehezkel, G.and Sagi, A. (2001). Physiological effects of methyl farnesoate and pyriproxyfen on wintering female crayfish Cherax quadricarinatus. Aquaculture, 202: 163-175. http://doi.org/10.1016/S0044-8486(01)00596-8

Aiken, D. and Waddy, S. L. (1980). Reproductive Biology [Lobsters]. The Biology and Management of Lobsters. Academic Press Limited, London

Balasubramanian, C. P.; Fierro, I. J. and Tsukimura, B. (2010). Stimulation of ovarian growth by methyl farnesoate and eyestalk ablation in penaeoidean model shrimp, Sicyonia ingentis Burkenroad, 1938). Aquac. Res., 41(12): 1887-1897. http://doi.org/10.1111/j.1365-2109.2010.02612.x

Borst, D. W.; Laufer, H., Landau, M., Chang, E. S., Hertz, W. A., Baker, F. C. and Schooley, D. A. (1987). Methyl farnesoate and its role in crustacean reproduction and development. Insect Biochem., 7(7): 1123-1127. http://doi.org/10.1016/0020-1790(87)90133-8

Borst, D. W.; Ogan, J., Tsukimura, B., Claerhout, T. and Holford, K. C. (2001). Regulation of the crustacean mandibular organ. Am. Zool., 41(3): 430-441. http://doi.org/10.1093/icb/41.3.430

Borst, D. W.; Wainwright, G. and Rees, H. H. (2002). In vivo regulation of the mandibular organ in the edible crab. Proc. Rl. Soc. Lond. Biol. Sci., 269(1490): 483-490. http://doi.org/10.1098/rspb.2001.1870

Chang, E. S. (1997). Chemistry of crustacean hormones that regulate growth and reproduction. Recent Advances in Marine Biotechnology., 1: 163-178.

Charniaux-Cotton, H. and Payen, G. (1988). Crustacean Reproduction. In "Endocrinology of Selected Invertebrate Types." Laufer, H. \& Downer, R.G.H. (Eds), Alan R. Liss, New York. pp. 279-303.

Coccia, E.; Lisa, E., Cristo, C., Cosmo, A. and Paolucci, M. (2010). effects of estradiol and progesterone on the reproduction of the freshwater crayfish Cherax albidus. Biol. Bul., 218: 36-47. http://doi.org/10.1086/BBLv218n1p36

Fairs, N. J.; Quinian, P. T. and Goad, L. J. (1990). Changes in ovarian unconjugated and conjugated steroid titers during vitellogenesis in Penaeus monodon. Aquaculture., 89(1): 83-99. http://doi.org/10.1016/0044-8486(90)90235-F

Hemalatha, M.; Parameswari, K., Kishori, B., Reddy, B. S. and Reddy, P. R. (2016). Methyl farnesoate induced ovarian maturation in freshwater prawn, Macrobrachium rosenbergii. J. Oceanogr. Mar. Res., 4: 142. http://doi.org/ $10.4172 / 2572-3103.1000142$ 
Kalavathy, Y.; Mamatha, P. and Reddy, P. S. (1999). Methyl farnesoate stimulates testicular growth in the freshwater crab Oziotelphusa senex senex Fabricius. Naturwissenschaften., 6(8): 394-395. http://doi.org/10.1007/s001140050639

Kale, R. S.; Shejule, K. B., Kharat, P. S. and Sonawane, A. K. (2008). Induced ovarian maturation by $17 \alpha$-hydroxyprogesterone hormone in freshwater crab, Barytelphusa cunicularis. J. Aquat. Biol., 23(2): 109-112.

Kraisuwansopit, A.; Limsakul, S., Mahasawasde, S. and Meunpol, O. (2008). Ultrastructure of sesquiterpenoid and eicosanoid producing organ from sandworm (perinereis sp.) and effect of the extracts on marine shrimp ovarian maturation. In 46. Kasetsart University Annual Conference, Bangkok (Thailand).

Kulkarni, G.; Nagabhushanam, R. and Joshi, P. (1979). Effect of progesterone on ovarian maturation in a marine penaeid prawn Parapenaeopsis hardwickii (Miers, 1878). Ind. J. Exp. Biol., 17: 86-987.

Landau, M.; Laufer, H. and Homola, E. (1989). Control of Methyl Farnesoate Synthesis in the Mandibular Organ of the Crayfish Procambarus clarkii: Evidence for Peptide Eurohormones with Dual Functions. Inver. Reprod. Develop., 16(1-3): 165-168. http://doi.org/10.1080/07924259.1989.9672073

Laufer, H. (1992). Methods for Increasing Crustacean Larval Production. US Patent $5,161,481$.

Laufer, H.; Biggers, W. J. and Ahl, J. S. (1998). Stimulation of ovarian maturation in the crayfish Procambarus clarkii by methyl farnesoate. Gen. Comp. Endocrinol., 111(2): 113-118. http://doi.org/10.1006/gcen.1998.7109.

Laufer, H.; Borst, D., Baker, F. C., Reuter, C. C., Tsai, L. W., Schooley, D. A., Sinkus, M. (1987). Identification of a juvenile hormone-like compound in a crustacean. Science., 235(4785): 202-205. http://doi.org/10.1126/science. 235.4785.202

Laufer, H.; Sagi, A. and Ahl, J. S. B. (1994). Alternate mating strategies of polymorphic males of Libinia emarginata appear to depend on methyl farnesoate. Inver. Reprod. Develop., 26(1): 41-44. http://doi.org/10.1080/ 07924259.1994.9672399

Medesani, D. A.; Ferre, L. E., Canosa, I. S., Silveyra, G. R. and Rodriguez, E. M. (2015). Induction of vitellogenesis by 17- hydroxyprogesterone and methyl farnesoate during postreproductive period, in the estuarine crab Neohelice granulate. Inver. Reprod. Develop., 59: 104-110.

Merlin, J.; Mohanlal, D. L., Balasubramanian, C. P., Sherly, T., Subramoniam, T., Syamadayal, J.,Vijayan, K. K. (2015). Induction of vitellogenesis and reproductive maturation in tiger shrimp, Penaeus monodon by 17ß-estradiol and 17 $\alpha$-hydroxyprogesterone: in vivo and in vitro studies. Inver. Reprod. Develop., 59(3): 166-175. http://doi.org/10.1080/07924259.2015.1051192

Muhd-Farouk, H.; Jasmani, S. and Ikhwanuddin, M. (2016). Effect of vertebrate steroid hormones on the ovarian maturation stages of orange mud crab, Scylla olivacea (Herbst, 1796). Aquaculture., 451: 78-86. http://doi.org/10.1016/ j.aquaculture.2015.08.038

Nagabhushanam, R. S.; Sambasiva, R., Sarojini, R. and Jayalakshmi, K. (1987). Annual reproductive cycle of female Metapenaeus affinis. National Symposium on Physiology of Crustaceans., 39-41.

Nagaraju, G. P. C. (2007). Is methyl farnesoate a crustacean hormone?. Aquaculture., 272(1-4): 39-54. http://doi.org/10.1016/j.aquaculture.2007.05.014 
Nagaraju, G. P. C. (2011). Reproductive regulators in decapod crustaceans: an overview. J. Exp. Biol., 214: 3-16. http://doi.org/10.1242/jeb.047183

Nagaraju, G. P. C. and Borst, D. W. (2008). Methyl farnesoate couples environmental changes to testicular development in the crab Carcinus maenas. J. Exp. Biol.,

211: $\quad$ 2773. http://doi.org/10.1242/jeb.019133

Nagaraju, G. P. C.; Ramamurthi, R. and Reddy, P. S. (2002). Methyl farnesoate stimulates ovarian growth in Penaeus indicus. In V.S. Harikumar (Ed), Recent Trends in Biotechnology Agrobios, India. pp. 85-89.

Nagaraju, G. P. C.; Reddy, P. R. and Reddy, P. S. (2006). In vitro methyl farnesoate secretion by mandibular organs isolated from different molt and reproductive stages of the crab Oziotelphusa senex senex. Fish. Sci., 7(2): 410-414. http://doi.org/10.1111/j.1444-2906.2004.00816.x

Nagaraju, G.P.C.; Suraj, N. and Reddy, P.S. (2003). Methyl farnesoate stimulates gonad development in Macrobrachium malcolmsonii (H. Milne Edwards) (Decapoda, Palaemonidae). Crustaceana, 76(10): 1171-1178.

Okumura, T. and Sakiyama, K. (2004). Hemolymph levels of vertebrate-type steroid hormones in female kuruma prawn Marsupenaeus japonicus (Crustacea: Decapoda: Penaeidae) during natural reproductive cycle and induced ovarian development by eyestalk ablation. Fish. Sci., 70: 372-380.

Reddy, B. S. and Reddy, P.R. (2015). Methyl farnesoate induced ovarian vitellogenin synthesis in freshwater rice field crab Oziothelphusa senex senex Fabricus, Journal of Infertility and Reproduction Biol., 3: 237-244.

Reddy, B. S.; Sridevi, V., Neelima, H., Reddy, P. R. and Reddy, P. S. (2016). Regulation of vitellogenesis by selected endocrine modulators in crab Oziothelphusa senex senex, with special reference to methyl farnesoate. Aquaculture Reports., 3: 24-30. http://doi.org/10.1016/j.aqrep.2015.11.006

Reddy, P. R.; Kiranmayi, P., Kumari, K. T. and Reddy, P. S. (2006). 17 Beta-hydroxy progesterone induced ovarian growth and vitellogenesis in the freshwater rice field crab,Oziotelphusa senex senex. Aquaculture., 254: 768-775. http://doi.org/10.1016/j.aquaculture.2005.11.023

Reddy, P. S. and Ramamurthi, R. (1998). Methyl farnesoate stimulates ovarian maturation in the freshwater crab Oziotelphusa senex senex Fabricius. Curr. Sci., 68-70.

Reddy, P. S.; Reddy, P. R. and Nagaraju, G. P. C. (2004). The synthesis and effects of prostaglandins on the ovary of the crab Oziotelphusa senex senex. Gen. Comp. Endocrinol., 135(1): 35-41. http://doi.org/10.1016/j.ygcen.2003.08.002

Riley, L. G. and Tsukimura, B. (1998). Yolk protein synthesis in the riceland tadpole shrimp, Triops longicaudatus, measured by in vitro incorporation of $3 \mathrm{H}-$ leucine. J. $\quad$ Exp. Zool., 281: 238-247. http://doi.org/10.1002/(SICI)1097010X(19980615)281:3<238::AID-JEZ10>3.0.CO;2-7

Rodriguez, E. M.; Lopez Greco L. S., Medesani, D. A., Laufer, H. and Fingerman, M. (2002a). Effect of methyl farnesoate, alone and in combination with other hormones, on ovarian growth of the red swamp crayfish, Procambarus clarkii, during vitellogenesis. Gen. Comp. Endocrinol., 125: 34-40. http://doi.org/10.1006/gcen.2001.7724

Rodriguez, E.M.; Medesani, D. A., Greco, L. S. L. and Fingerman, M. (2002b). Effects of some steroids and other compounds on ovarian growth of the red swamp crayfish, Procambarus clarkii, during early vitellogenesis. J. Exp. Zool., 292(1): 82-87. http://doi.org/10.1002/jez.1144 
Rotllant, G.; Takac, P., Liu, L., Scott, G. L. and Laufer, H. (2000). Role of ecdysteroids and methyl farnesoate in morphogenesis and terminal moult in polymorphic males of the spider crab Libinia emarginata. Aquaculture., 190(1-2):103-118. http://doi.org/10.1016/S0044-8486(00)00388-4

Sagi, A.; Homola, E. and Laufer, H. (1993). Distinct reproductive types of male spider crabs Libinia emarginata differ in circulating and synthesizing methyl farnesoate. Biol. Bull., 185(2): 168-173. http://doi.org/10.2307/1541997

Sarojini, R.; Rao, S. S. and Lakshmi, K. J. (1990). Effect of steroids (estradiol and estrone) on the ovaries of the marine crab, Scylla serrate. Comp. Physiol. Ecol., 15(1): 21-26.

Sasikala, S. L. and Subramoniam, T. (1991). Influence of juvenile hormone JH III on ovarian activity of adult paddy field crab Paratelphusa hydrodromous Herbst. Indian. J. Exp. Biol., 29(5): 426-429.

Skinner, D. M. (1985). Molting and regeneration. The Biology of Crustacea, 9: 43-146.

Sujathamma, A. and Dayakar, Y. (2015). Effect of estradiol and $17 \alpha$ hydroxyprogesterone on ovarian development of fresh water paddy field crab Oziotelphusa senex senex (Fabricius), Euro. J. Exp. Bio., 5(9): 27-30.

Suneetha, Y.; Jyothi, P. and Reddy, M. (2010). Impact of methyl farnesoate in the regulation of molting and reproduction in the tropical penaeid prawn Penaeus monodon. Global Journal of Biotechnology and Biochemistry., 5: 75-79.

Swetha, C. H.; Girish, B. P. and Reddy, P. S. (2016). Elucidation of the role of estradiol and progesterone in regulating reproduction in the edible crab, Oziothelphusa senex senex. RSC Advances, 6: 24959-24967. http://doi.org/ 10.1039/C5RA23637A

Tsukimura, B. (2001). Crustacean vitellogenesis: its role in oocyte development. Amer. Zool., 41: 465-476.

Tsukimura, B. and Kamemoto, F. I. (1991). in vitro stimulation of oocytes by presumptive mandibular organ secretions in the shrimp, Penaeus vannamei. Aquaculture., 92: 59-66. http://doi.org/10.1016/0044-8486(91)90008-U

Tsukimura, B.; Kamemoto, F. I. and Borst, D. W. (1993). Cyclic nucleotide regulation of methyl farnesoate synthesis by the mandibular organ of the lobster, Homarus americanus. J. Exp. Zool., 265(4): 427-431. http://doi. org/ 10.1002/jez.1402650412

Tsukimura, B.; Nelson, W. K, and Linder, C. J. (2006). Inhibition of ovarian development by methyl farnesoate in the tadpole shrimp, Triops longicaudatus. Comp Biochem Physiol.,144(2): 135-144. http://doi.org/10.1016/j.cbpa.2006.02.015

Wilder, M. N.; Okumura, T., Suzuki, Y., Fusetani, N. and Aida, K. (1994). Vitellogenin production induced by eyestalk ablation in juvenile giant freshwater prawn Macrobrachium rosenbergii and trial methyl farnesoate administration. Zool. Sci., $11(1)$ : 45-53.

Yano, I. and Hoshino, R. (2006). Effects of 17ß-estradiol on the vitellogenin synthesis and oocyte development in the ovary of kuruma prawn, Marsupenaeus japonicas. Aquaculture., 144: 18-23. http://doi. org/10.1016/ j.cbpa.2006.01.026

Zapata, V.; Lopez Greco, L. S., Medesani, D. and Rodriguez, E. M. (2003). Ovarian growth in the crab, Chasmagnathus granulata induced by hormones and neuroregulators throughout the year. in vivo and in vitro studies. Aquaculture., 224(1-4): 339. http://doi.org/10.1016/S0044-8486(03)00226-6 